\title{
Erratum to: Neglect dyslexia: a review of the neuropsychological literature
}

\author{
Giuseppe Vallar - Cristina Burani $\cdot$ Lisa S. Arduino
}

Published online: 28 December 2010

(C) Springer-Verlag 2010

Erratum to: Exp Brain Res 206:219-235

DOI 10.1007/s00221-010-2386-0

The authors would like to correct the following two errors that they overlooked prior to publication:

- In Table 1 on p. 223, the VFD for patient NT (Friedmann and Nachman-Katz 2004) should be "-" not “+”.

- On p. 230 in the right-hand column, in the 4th line from the bottom of the page, it should read "In six patients..." not in "In three patients...".

The online version of the original article can be found under doi:10.1007/s00221-010-2386-0.

G. Vallar $(\bowtie)$

Department of Psychology, University of Milano-Bicocca, Edificio U6, Piazza dell'Ateneo Nuovo 1, 20126 Milan, Italy

e-mail: giuseppe.vallar@unimib.it

G. Vallar

IRCCS Italian Auxological Institute, Milan, Italy

C. Burani · L. S. Arduino

Institute of Cognitive Sciences and Technologies,

CNR, Rome, Italy

L. S. Arduino

University LUMSA, Rome, Italy 